\title{
Formation of Indium-Doped Zinc Oxide Thin Films Using Ultrasonic Spray Pyrolysis: The Importance of the Water Content in the Aerosol Solution and the Substrate Temperature for Enhancing Electrical Transport
}

\author{
Rajesh Biswal $^{1}$, Luis Castañeda ${ }^{2, *}$, Rosario Moctezuma ${ }^{3}$, Jaime Vega-Pérez ${ }^{4}$, María De La
} Luz Olvera ${ }^{1}$ and Arturo Maldonado ${ }^{1}$

1 Departamento de Ingeniería Eléctrica, Centro de Investigación y de Estudios Avanzados del Instituto Politécnico Nacional CINVESTAV-IPN, SEES, Apartado 14740, México; E-Mails: rroshan@cinvestav.mx (R.B.); molvera@cinvestav.mx (M.L.O.); amaldo@cinvestav.mx (A.M.)

2 Instituto de Física, Benemérita Universidad Autónoma de Puebla, Apartado Postal J-48, Puebla 72570, Mexico

3 Instituto de Ciencias Básicas e Ingeniería de la Universidad Autónoma del Estado de Hidalgo-AAMF, Pachuca 42184, México; E-Mail: rosario.moctezuma@gmail.com

4 Escuela Superior de Ingeniería Mecánica y Eléctrica Unidad Ticoman del Instituto Politécnico Nacional, Apartado Postal 07340, D.F., México; E-Mail: jvega@ipn.mx

* Author to whom correspondence should be addressed; E-Mail: luisca@ifuap.buap.mx; Tel.: +52-222-229-5500, Ext: 2045; Fax: +52-222-229-5611.

Received: 5 January 2012; in revised form: 10 February 2012 / Accepted: 29 February 2012 / Published: 12 March 2012

\begin{abstract}
Indium doped zinc oxide [ZnO:In] thin films have been deposited at $430^{\circ} \mathrm{C}$ on soda-lime glass substrates by the chemical spray technique, starting from zinc acetate and indium acetate. Pulverization of the solution was done by ultrasonic excitation. The variations in the electrical, structural, optical, and morphological characteristics of $\mathrm{ZnO}: \mathrm{In}$ thin films, as a function of both the water content in the starting solution and the substrate temperature, were studied. The electrical resistivity of $\mathrm{ZnO}$ :In thin films is not significantly affected with the increase in the water content, up to $200 \mathrm{~mL} / \mathrm{L}$; further increase in water content causes an increase in the resistivity of the films. All films show a polycrystalline character, fitting well with the hexagonal $\mathrm{ZnO}$ wurtzite-type structure. No preferential growth in samples deposited with the lowest water content was observed, whereas an increase in water content gave rise to a (002) growth. The surface morphology of the films
\end{abstract}


shows a consistency with structure results, as non-geometrical shaped round grains were observed in the case of films deposited with the lowest water content, whereas hexagonal slices, with a wide size distribution were observed in the other cases. In addition, films deposited with the highest water content show a narrow size distribution.

Keywords: zinc oxide; thin solid films; ultrasonic spray pyrolysis

PACS: 68.55.-a; 68.55.Jk; 81.10.Dn; 81.15.Rs

\section{Introduction}

Zinc oxide $(\mathrm{ZnO})$ in thin film form shows a wide variety of controlled properties, such as piezoelectricity, gas chemisorption, photo-catalysis, high conductivity, and transparency in the visible spectrum, that can be exploited in the design and manufacture of optoelectronic and electronic devices as well as in catalysis and biology fields [1-3].

According to the required application, the deposition of $\mathrm{ZnO}$ thin films can be done successfully by different physical techniques, as is the case of sputtering [4], reactive evaporation [5], pulsed laser deposition [6], and chemical techniques - sol-gel [7], chemical bath [8], chemical vapor deposition (CVD) [9], and chemical spray (CST) [10]. Among these deposition techniques, CST has been refined over the years for industrial applications due to the direct implementation of large area deposition using low cost equipment [11]. Additionally, for transparent conductors, chemically sprayed as-grown films do not require an extra annealing step and it can also be considered as a key technique for future developments in nano-scale manufacturing [12].

Focusing only on CST, there have been extensive studies on the effect of deposition variables on the physical characteristics of $\mathrm{ZnO}$ thin films [13-18]. However, all this time CST has not remained the same, since substantial modifications in the set up have been successfully tried in order to enhance the characteristics of the films. The atomization process can play a key role in the deposition of $\mathrm{ZnO}$ thin films with high transmittance and conductivity, as well as textured surface, adequate for transparent electrodes in thin film solar cells. As a matter of fact, the ultrasonic atomization process generates smaller droplets than the conventional pneumatic process, which in turn yield films with a smoother surface and enhanced conductivity.

The effect of deposition variables on the characteristics of undoped [19-20] and doped $\mathrm{ZnO}$ films [21-29] deposited with ultrasonic spray pyrolysis has been reported. It is worthy to note that the number of reports of $\mathrm{ZnO}$ thin films based on ultrasonic process is increasing, although not yet at the same depth of knowledge than those based on pneumatic process. In this respect, some home-made adapted equipment, including commercial nebulizers, have been used for depositing conductive and transparent $\mathrm{ZnO}$ thin films, as is noted in different reports. Unfortunately, this influences the number of reports regarding $\mathrm{ZnO}$ dependence on deposition variables. Therefore, a lack of knowledge about some deposition variables, affecting the performance of $\mathrm{ZnO}$ thin films as transparent and conductive materials is still present in the literature. The effect of solvent composition, which is relevant in the deposition process as the gaseous species formed affect the final structure of films, has been pointed 
out previously by Smith and Rodriguez Clemente [30]. Finding some correlation between deposition conditions and physical characteristics of the $\mathrm{ZnO}$ thin films was expected. The main goal of our study was the optimization of the deposition conditions in order to manufacture highly conductive and transparent $\mathrm{ZnO}$ thin films on glass substrates by ultrasonic chemical spray, avoiding extra steps such as a previous synthesis, complex reactor design and annealing on vacuum, or reducing atmospheres.

In this work the effect of water content variation in the starting solution on the electrical, structural, morphological, and optical characteristics of indium doped zinc oxide thin films, deposited by chemical spray at $430^{\circ} \mathrm{C}$, is studied.

\section{Experimental Details}

\subsection{Fabrication Of Indium Doped Zinc Oxide [ZnO:In] Thin Films}

$\mathrm{ZnO}$ :In thin solid films were prepared using the ultrasonic spray pyrolysis (USP) technique (Figure 1), which is a versatile technique that can be used to produce nanoscale sized powders and thin solid films. With this method the particle's size can be easily controlled by changing the concentration in the starting solution and the atomization parameters. The deposition system used for depositing the $\mathrm{ZnO}$ :In thin films presented in this work includes a piezoelectric transducer operating at variable frequency, which was set to $1.2 \mathrm{MHz}$ and the ultrasonic power at $120 \mathrm{~W}$.

$\mathrm{ZnO}:$ In thin films were deposited on $2.54 \mathrm{~cm} \times 2.54 \mathrm{~cm}$ soda-lime glass substrates from five different starting solutions. The starting solutions were prepared from a $0.2 \mathrm{M}$ solution of zinc (II) acetate $\left(\left[\mathrm{Zn}\left(\mathrm{O}_{2} \mathrm{CCH}_{3}\right)_{2}\right]\right.$ from Alfa, 98\%), dissolved in a mix of deionized water, acetic acid $\left(\left[\mathrm{CH}_{3} \mathrm{CO}_{2} \mathrm{H}\right]\right.$ from Baker, 95\%), and methanol $\left(\left[\mathrm{CH}_{3} \mathrm{OH}\right]\right.$ from Baker, 98\%). For a $1 \mathrm{~L}$ solution the acetic acid quantity was fixed to $50 \mathrm{~mL} / \mathrm{L}$ in all cases. Separately, a $0.2 \mathrm{M}$ solution of indium (III) acetate $\left(\left[\mathrm{In}\left(\mathrm{CH}_{3} \mathrm{CO}_{2}\right)_{3}\right]\right.$ from Alfa, $\left.98 \%\right)$ dissolved in a mix of deionized water and acetic acid ( $1: 1$, volume proportion) was prepared in order to be used as doping solution. A constant [In]/[Zn] ratio of 3.0 at.\% was used. The five starting solutions were prepared with different water contents, namely, (M1) $50 \mathrm{~mL} / \mathrm{L}$, (M2) $100 \mathrm{~mL} / \mathrm{L}$, (M3) $150 \mathrm{~mL} / \mathrm{L}$, (M4) $200 \mathrm{~mL} / \mathrm{L}$, and (M5) $300 \mathrm{~mL} / \mathrm{L}$. Finally methanol was added until $1 \mathrm{~L}$ was completed. The substrates were cleaned prior to deposition. The cleaning process of the substrates is as follows: (i) sonication for five minutes in trichloroethylene $\left(\left[\mathrm{C}_{2} \mathrm{HCl}_{3}\right]\right.$ from Baker, 98\%) for degreasing the substrates; followed by (ii) sonication in methyl alcohol ([CH $3 \mathrm{OH}]$ from Aldrich, 98\%); (iii) sonication in acetone $\left(\left[\mathrm{CH}_{3} \mathrm{COCH}_{3}\right]\right.$ from Baker, $\left.98 \%\right)$, and finally, (iv) the substrates are dried by a jet of pure and dry nitrogen ([ $\left.\mathrm{N}_{2}\right]$ from PRAXAIR, 99.997\%). Then the substrates are placed on a fused tin bath, whose temperature measured just below the substrate using a chromel-alumel thermocouple, which is contained in a stainless steel metal jacket. The substrate temperature $\left(T_{s}\right)$ was kept constant at $430{ }^{\circ} \mathrm{C}$, within an accuracy of $\pm 0.5^{\circ} \mathrm{C}$. Pure $\mathrm{N}_{2}$ (from PRAXAIR, 99.997\%) was used as solution carrier and director gas, with flow rates of 3.5 and $0.5 \mathrm{~L} \cdot \mathrm{min}^{-1}$, respectively. 
Figure 1. Schematic diagram of the experimental set up used for depositing the $\mathrm{ZnO}$ :In thin films (ultrasonic spray pyrolysis: USP).

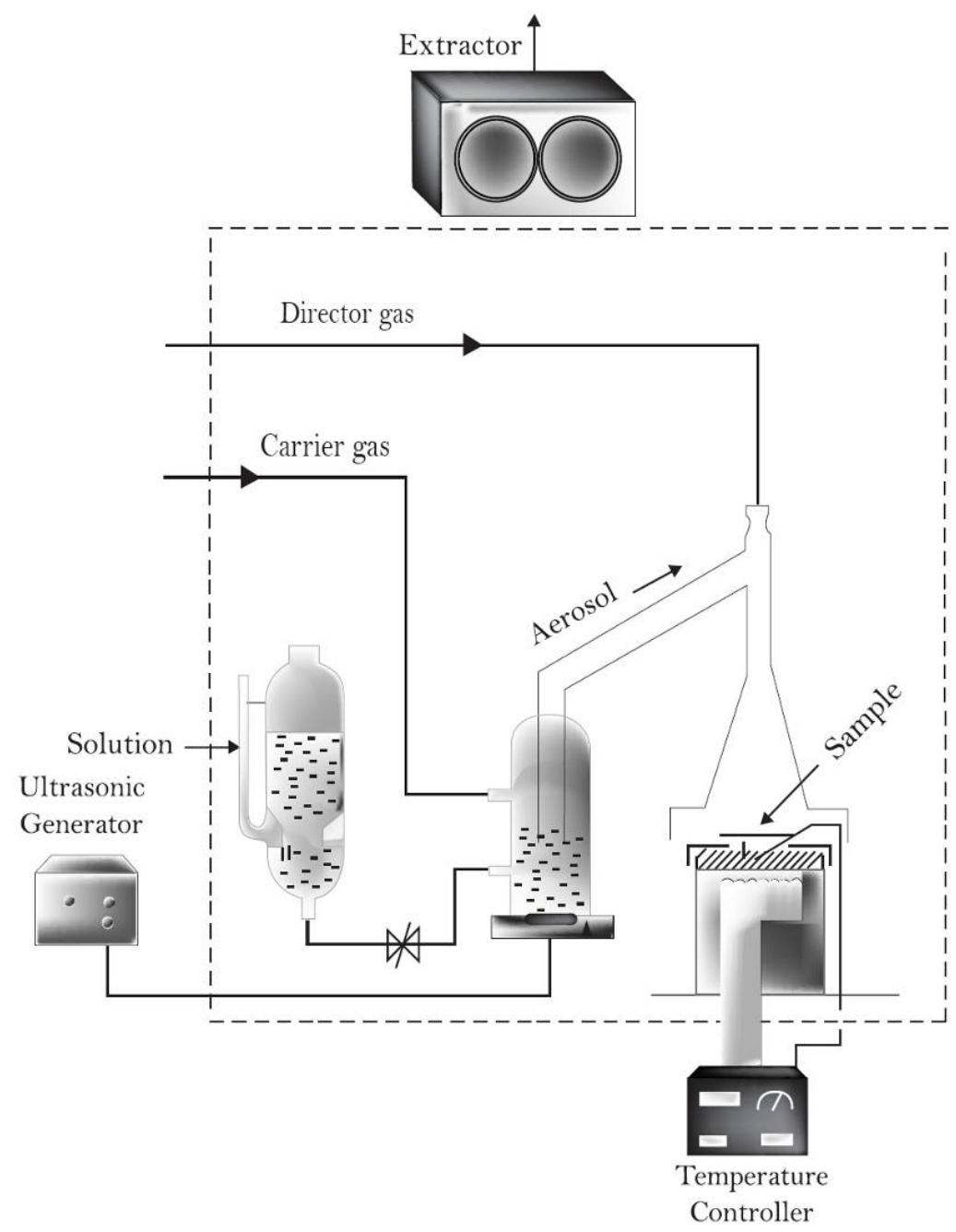

\subsection{Indium-Doped Zinc Oxide Thin Solids Films Analysis}

The thickness of the $\mathrm{ZnO}$ :In thin films was measured by a KLA profilometer (Tencor model P15 with a resolution of $1.5 \mathrm{~nm}$ ) on a step formed during deposition. All the samples were grown with a film thickness value around $800 \mathrm{~nm}$. The microcrystalline structure was studied from X-ray diffraction analysis of the samples made in a Siemens D5000 diffractometer by using the $\mathrm{Cu}-\mathrm{K}_{1}$ $(\lambda=0.154056 \mathrm{~nm})$ radiation and the $\theta-2 \theta$ technique. A JEOL scanning electron microscope (SEM) was used for morphological and composition evaluation of the thin solid films. The optical transmittance spectra at normal incidence were obtained by a double-beam Shimadzu 2401 PC spectrophotometer, in the UV-Vis region (350-1000 nm) without glass substrate correction. Electrical sheet resistance of samples was measured by the conventional four-aligned probe method (Veeco equipment) with the appropriate geometric correction factors. 


\section{Results and Discussion}

\subsection{Structural Properties}

X-ray diffraction patterns obtained from $\mathrm{ZnO}$ thin films show polycrystalline characteristics and the corresponding peaks fit well to a hexagonal $\mathrm{ZnO}$ wurtzite type structure in all cases. However, changes in the intensity of the peaks were observed according to the deposition conditions. Figure 2 shows the patterns of $\mathrm{ZnO}$ :In thin films deposited at $430{ }^{\circ} \mathrm{C}$ with different water contents in the starting solution. It can be seen that the sample deposited with the lowest water quantity does not shows a preferential growth with respect to the low order reflections. However, when water content increases to $100 \mathrm{~mL} / \mathrm{L}$, the corresponding spectrum of $\mathrm{ZnO}$ :In films shows the (002) intensity prevailing over all the rest. High order reflections exhibit only a marginal contribution. This situation is presented in all remaining cases.

The crystallite size was estimated using the (002) and (100) diffraction peaks from the XRD data in accordance with the Debye-Scherer formula [31]:

$$
D=\frac{0.9 \lambda}{B \cos \theta}
$$

where $D$ is the crystallite size in nanometers, $\lambda$ is the wavelength value of the $\mathrm{Cu} K_{\alpha 1}$ line, $\theta$ is the Bragg diffraction angle and $B$ is the FWHM of the diffraction peak measured in radians. According to these results, the crystallite size of the $\mathrm{ZnO}$ :In thin films decreases from 36 to $23 \mathrm{~nm}$ as the deionized water concentration is increased in the starting solution.

Figure 2. X-ray diffraction patterns of $\mathrm{ZnO}$ :In thin films deposited at $430{ }^{\circ} \mathrm{C}$ from the starting solutions with different water content.

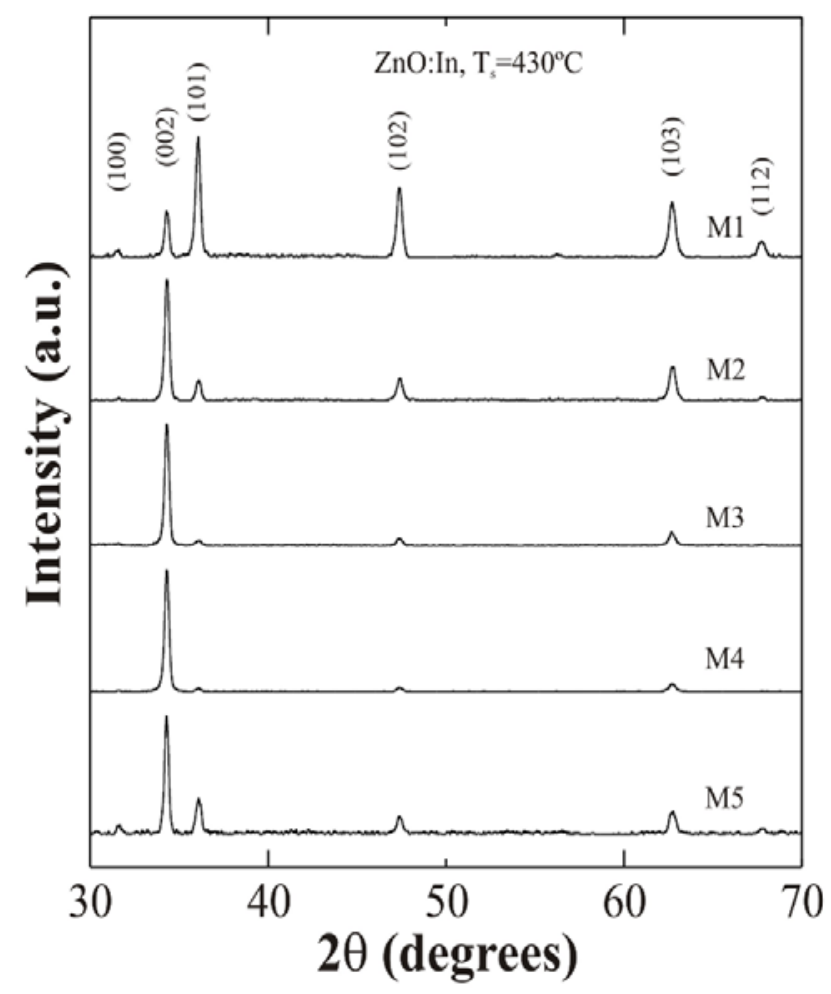




\subsection{Scanning Electron Microscopy Studies}

Figure 3(a) shows the surface morphology of $\mathrm{ZnO}$ :In thin films deposited at $430{ }^{\circ} \mathrm{C}$ from different water contents in the starting solution. In the case of films deposited with $50 \mathrm{~mL} / \mathrm{L}$, two grain sizes; round shaped grains with an average size of $120 \mathrm{~nm}$, and others not well defined, elongated and bigger, with an average size of $1 \mu \mathrm{m}$, were observed. At higher zoom it is possible to note that the surface of these grains is covered by an agglomeration of smaller grains. The films deposited from a solution with water content of $100 \mathrm{~mL} / \mathrm{L}$ show a dramatic change, owing to the fact that at this stage the grains present a well defined shape, namely hexagonal slices with a wide size distribution, as it can be seen in Figure 3(b). Size distribution ranging from 150 to $800 \mathrm{~nm}$ was observed. In addition, stacking of hexagonal slices was also observed. Figure 3(c) shows the morphology of samples deposited with a water content of $200 \mathrm{~mL} / \mathrm{L}$ in the starting solution; a decrease in the fraction of smaller grains, formed by hexagonal shaped thin slices, is observed as well as a decrease in the size of the bigger grains. In fact, the maximum size is now in the order of $700 \mathrm{~nm}$. Figure 3(d) shows the morphology of ZnO:In thin films deposited with the highest water content, namely $300 \mathrm{~mL} / \mathrm{L}$. Hexagonal slices can again be observed, but now with a uniform grain size, in the order of $350 \mathrm{~nm}$. A small fraction, in the order of $10 \%$ is formed by grains with a smaller size. No stacking of hexagonal slices was observed in this case. It should be noted that as the water content increases, the grain size of $\mathrm{ZnO}$ samples, measured in the SEM micrographs, decreases; whereas the corresponding crystallite size, estimated from $\mathrm{X}$ ray diffraction data, shows a marginal increase. The effect of water content on the morphology and distribution grain size of $\mathrm{ZnO}$ :In thin films is apparent.

Figure 3. SEM micrographs of $\mathrm{ZnO}$ :In thin films deposited at $430{ }^{\circ} \mathrm{C}$ from starting solutions with different water contents: (a) $50 \mathrm{~mL} / \mathrm{L}$, (b) $100 \mathrm{~mL} / \mathrm{L}$, (c) $200 \mathrm{~mL} / \mathrm{L}$, and (d) $300 \mathrm{~mL} / \mathrm{L}$.
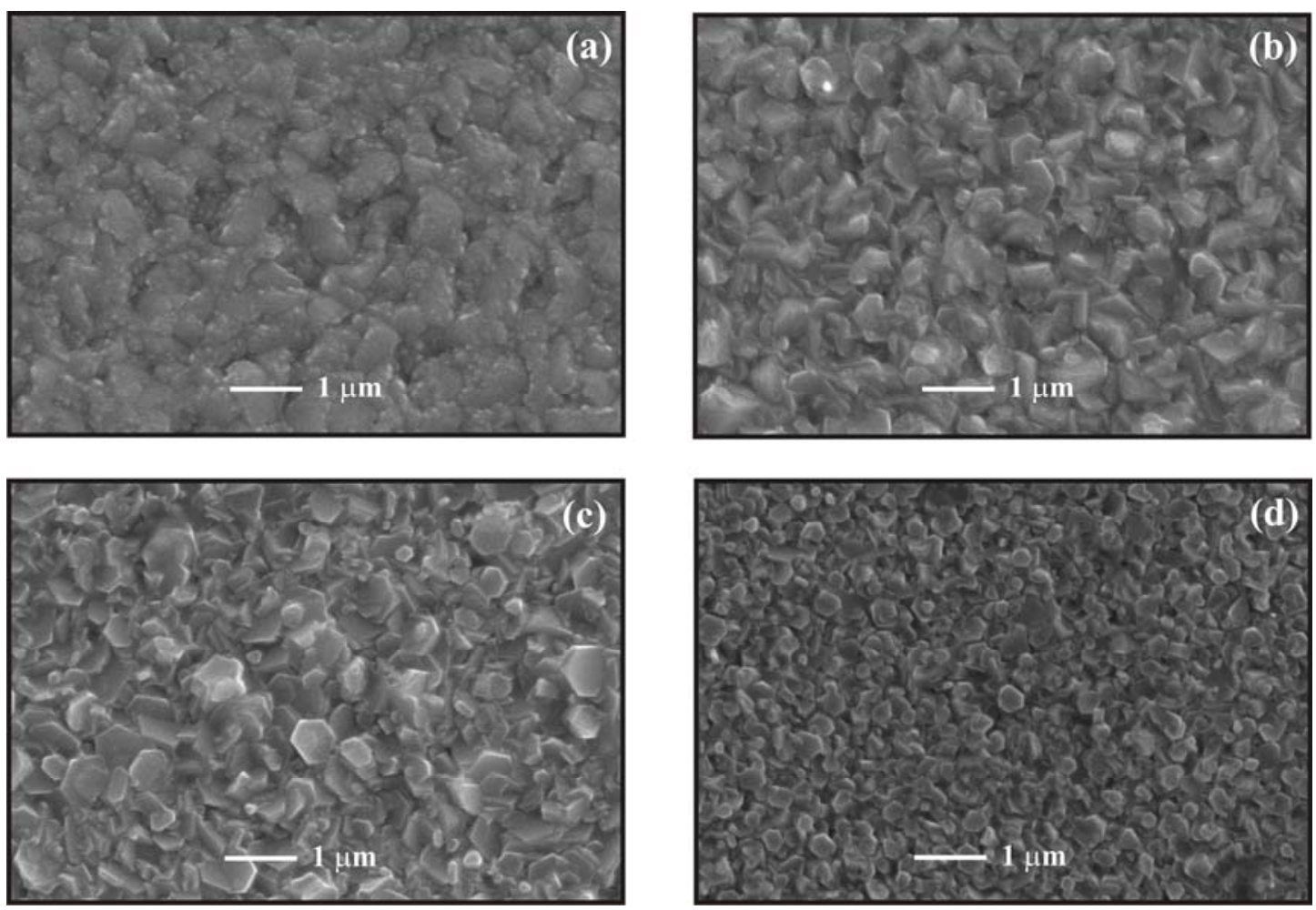


\subsection{Optical Properties}

Figure 4(a) shows the optical transmittance spectra of $\mathrm{ZnO}$ thin films deposited from starting solutions with different water contents. No substrate correction was made in the corresponding measurement. Average transmittance of all the films is suited for TCO application. In Table 1, the corresponding film thickness for every sample is shown. Optical band gap was calculated from the plot of $(\alpha h v)^{2}$ as a function of $h v$, where $\alpha$ is the optical absorption coefficient, and $h v$ is the energy of the incident photons. From these curves we can estimate the optical band gap $\left(E_{g}\right)$ values, by the extrapolation of straight line to $(\alpha h v)^{2}=0$. Figure 4(b) shows band gap values varying from 3.44 to $3.56 \mathrm{eV}$ as a function of water content in the starting solution.

Figure 4. (a) Optical transmittance spectra and (b) Plot of $(\alpha h v)^{2} v s$. hv.
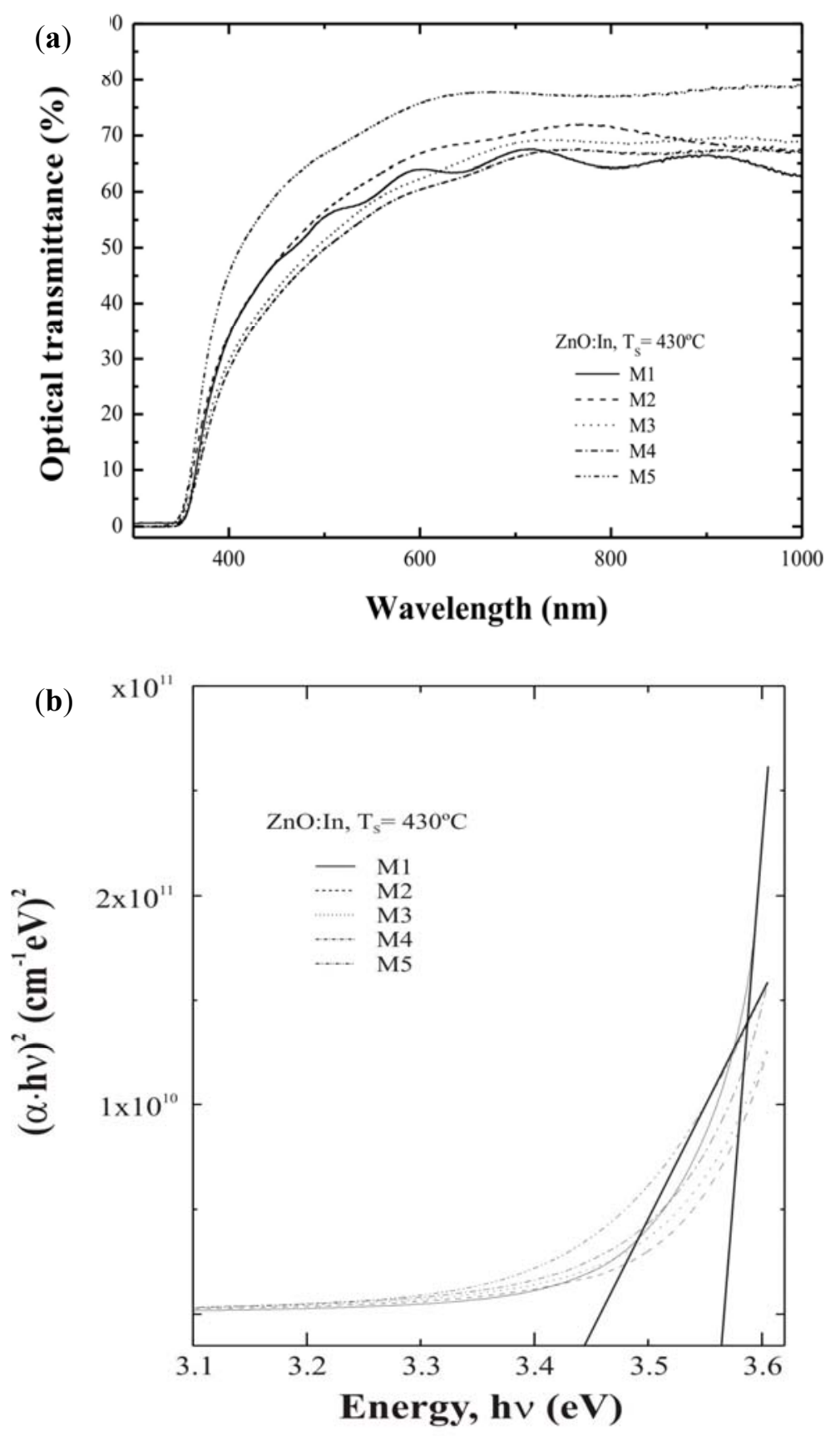


\subsection{Electrical Results}

Table 1 shows the electrical resistivity values for $\mathrm{ZnO}$ thin films deposited with solutions with different water contents, for fixed $\mathrm{T}_{\mathrm{S}}=430{ }^{\circ} \mathrm{C}$. A minimum in the resistivity value occurs for samples deposited with a water content of $100 \mathrm{~mL} / \mathrm{L}$. Further increase in water content causes an increase in the resistivity of $\mathrm{ZnO}$ thin films. The variation in water content in the starting solution for the deposition of $\mathrm{ZnO}$ thin films leads to substantial modification in the surface morphology. We believe this can be due to the characteristics of the deposition process. Namely, as the small drops travel toward the hot substrate, gradual evaporation of solvents occurs. This in turn causes an increase in the concentration of zinc salt lowering the corresponding $\mathrm{pH}$ of the solution. As a result, formation of irregular shaped grains of $\mathrm{ZnO}$ is observed. The increase in the water content changes the growth process, as the evaporation of solvents occurs more slowly, particularly the source of oxygen, water in this case, and increasing the chance for complete $\mathrm{ZnO}$ formation. In this case, $\mathrm{ZnO}$ with hexagonal slice shaped forms are obtained. However, in the low regime water content, a wide distribution in grain size is also observed that can be explained as a result of non-uniform distribution of oxygen source on the substrate, indicative of preferential nucleation around bigger grains. Further increase in water content, above a critical value, leads to the formation of grains with almost the same size, retaining the hexagonal slice shape. This effect can be due to the uniformity of oxygen content throughout the substrate, as a super-saturation of water occurs during the growth process, enhancing uniform grain growth. Consistency in morphology changes is also observed with the corresponding electrical results, as scattering of free carriers by grain boundaries is high in a film formed by hexagonal slice shaped grains, compared with an almost continuous growth occurring in films deposited with the lowest water content. The transmittance can be affected by texturing effect due to the water content on the characteristics of $\mathrm{ZnO}: \mathrm{In}$ thin solid films.

Table 1. The electrical resistivity and the band gap values for $\mathrm{ZnO}: \mathrm{In}$ thin films deposited with solutions with different water content, for fixed $\mathrm{TS}=430^{\circ} \mathrm{C} . \mathrm{V}_{\mathrm{H} 2 \mathrm{O}}=\mathrm{H}_{2} \mathrm{O}$ volume; $\mathrm{V}_{\text {Total }}=$ Total volume of $\mathrm{H}_{2} \mathrm{O}$.

\begin{tabular}{|c|c|c|c|c|c|c|}
\hline $\begin{array}{c}\text { ID } \\
\text { Sample }\end{array}$ & $\begin{array}{l}\mathbf{V}_{\mathrm{H} 2 \mathrm{O}} \\
/ \mathbf{V}_{\text {Total }}\end{array}$ & $\begin{array}{c}\text { Average } \\
\text { thickness (nm) } \\
\pm 5.0 \% \\
\end{array}$ & $\begin{array}{l}\text { Average transmittance } \\
\quad(400-700 \mathrm{~nm})(\%)\end{array}$ & $\begin{array}{c}\text { Average } \\
\text { transmittance } \\
(\text { at } 550 \mathrm{~nm})(\%) \\
\end{array}$ & $\begin{array}{c}\text { Electrical } \\
\text { Resistivity x10 } \\
(\mathbf{\Omega c m}) \pm \mathbf{5 . 0} \% \\
\end{array}$ & $\begin{array}{c}\text { Band gap ( } \mathrm{eV}) \\
\pm \mathbf{5 . 0 \%}\end{array}$ \\
\hline M1 & $50 / 1000$ & 673 & 56.87 & 58.97 & 1.54 & 3.56 \\
\hline M2 & $100 / 1000$ & 655 & 59.23 & 62.39 & 1.31 & 3.51 \\
\hline M3 & $150 / 1000$ & 680 & 55.08 & 58.19 & 1.90 & 3.49 \\
\hline M4 & $200 / 1000$ & 685 & 53.11 & 71.61 & 2.05 & 3.51 \\
\hline M5 & $300 / 1000$ & 435 & 69.05 & 79.61 & 10.17 & 3.44 \\
\hline
\end{tabular}

\section{Conclusions}

The role of water content on the characteristics of $\mathrm{ZnO}: \mathrm{In}$ thin films has been shown. Microstructure, morphology and electrical characteristics of the films can be achieved solely by solvent composition. Optimum deposition temperature conditions were obtained at $430{ }^{\circ} \mathrm{C}$. Some changes in the preferential growth, from random to highly oriented along the (002) planes in samples 
deposited at low and high temperatures, respectively, were observed. It is worth mentioning that by using the USP method, there is a great saving of reactants as compared with the pneumatic spray pyrolysis process. Based on these results, the $\mathrm{ZnO}$ :In thin films processed by ultrasonic spray pyrolysis show a great potential to be applied as transparent conducting electrodes in thin film solar cells with electrical conductivity close to doped $\mathrm{In}_{2} \mathrm{O}_{3}$, [ITO], and with appropriate high optical transmission in the near-UV, VIS and NIR. Further studies on the deposition of ZnO:In films and optimization of the implemented CST parameters should also be performed in order to improve the nonlinear optical response of the samples and film quality.

\section{Acknowledgments}

The technical assistance of M. A. Luna-Arias, A. G. López-Fabian and Adolfo Tavira-Fuentes is thanked. Special thanks are due to María de Lourdes-Rojas, from Laboratorios CentralesCINVESTAV-IPN for SEM analysis. This work was partially supported by CONACyT under contract Number 155996. L. Castañeda acknowledges financial support from the Instituto de Física, Vicerrectoría de Investigación y Estudios de Posgrado, Benemérita Universidad Autónoma de Puebla, and the Programa de Mejoramiento del Profesorado from the SEP México through project number PROMEP/103.5/09/4194. R. E. Moctezuma acknowledges financial support by the CONACyT through a postdoctoral scholarship.

\section{References}

1. Granqvist, C.G. Transparent conductors as solar energy materials: A panoramic review. Mater. Sol. Cells 2007, 91, 1529-1598.

2. Beyer, W.; Hüpkes, J.; Stiebig, H. Transparent conducting oxide films for thin film silicon photovoltaics. Thin Solid Films 2007, 516, 147-154.

3. Dastjerdi, R.; Montazer, M. Review: A review on the application of inorganic nano-structured materials in the modification of textiles: Focus on anti-microbial properties. Colloid. Surface. B 2010, 79, 5-18.

4. Bowen, A.; Li, J.; Lewis, J.; Sivaramakrishnan, K.; Alford, T.L.; Iyer, S. The properties of radio frequency sputtered transparent and conducting $\mathrm{ZnO}: \mathrm{F}$ films on polyethylene naphthalate substrate. Thin Solid Films 2011, 519, 1809-1816.

5. Wang, X.J.; Lei, Q.S.; Xu, W.; Zhou W.L. Preparation of ZnO:Al thin film on transparent TPT substrate at room temperature by RF magnetron sputtering technique. Mater. Lett. 2009, 63, 1371-1373.

6. Jayakumar, O.D.; Tyagi, A.K. Effect of oxygen pressure on room-temperature ferromagnetism of Al co-doped $\mathrm{Mn}$ doped $\mathrm{ZnO}$ thin films prepared by pulsed laser deposition. Int. J. Nanotechnol. 2011, 7, 1047-1053.

7. Li, Y.; Xu, L.; Li, X.; Shen, X.; Wang, A. Effect of aging time of $\mathrm{ZnO}$ sol on the structural and optical properties of $\mathrm{ZnO}$ thin films prepared by sol-gel method. Appl. Surf. Sci. 2010, 256, 4543-4547.

8. Hornok, V.; Pal, E.; Oszko, A.; Dekany, I. Hydrothermal synthesis of prism-like and flower-like $\mathrm{ZnO}$ and indium-doped $\mathrm{ZnO}$ structures. Colloid. Surf. A 2009, 340, 1-9. 
9. Nolan, M.G.; Hamilton, J.A.; O’Brien, S.; Bruno, G.; Pereira, L.; Fortunato, E.; Martins, R.; Povey, I.M.; Pemble, M.E. The characterisation of aerosol assisted CVD conducting, photocatalytic indium doped zinc oxide films. J. Photochem. Photobiol. A Chem. 2011, 219, $10-15$.

10. Qin, X.J.; Jan, S.H.; Zhao, Z.L.; Suo, H.T.; Song, S.T. Fabrication of transparent conductive al-doped zno thin films by aerosol-assisted chemical vapour deposition. Inorg. Mater. 2011, 26, 607-612.

11. Chamberlin, R.R.; Skarman, J.S. Chemical spray deposition process for inorganic films. J. Electrochem. Soc. 1966, 113, 86-89.

12. Patil, P.S. Review versatility of chemical spray pyrolysis technique. Mater. Chem. Phys. 1999, 59, 185-198.

13. Chopra, K.L.; Major, S.; Pandya, D.K. Transparent conductors, a status review. Thin solid Films 1983, 102, 1-46.

14. Romero, R.; Leinen, D.; Dalchiele, E.A.; Ramos-Barrado, J.R.; Martín, F. The effects of zinc acetate and zinc chloride precursors on the preferred crystalline orientation of $\mathrm{ZnO}$ and Al-doped ZnO thin films obtained by spray pyrolysis. Thin Solid Films 2006, 515, 1942-1949.

15. Vimalkumar, T.V.; Poornima, N.; Sudha, K.C.; Vijayakumar, K.P. On tuning the orientation of grains of spray pyrolysed ZnO thin films. Appl. Surf. Sci. 2010, 256, 6025-6028.

16. Josepha, B.; Gopchandrana, K.G.; Thomasa, P.V.; Koshyb, P.; Vaidyan, V.K. A study on the chemical spray deposition of zinc oxide thin films and their structural and electrical properties. Mater. Chem. Phys. 1999, 58, 71-77.

17. Krunks, M.; Karber, E.; Katerski, A.; Otto, K.; Oja, A.I.; Dedova, T.; Mere, A. Solar Extremely thin absorber layer solar cells on zinc oxide nanorods by chemical spray. Sol. Energ. Mat. Sol. C. 2010, 94, 1191-1195.

18. Zaier, A.; Oum, E.F.; Lakfif, F.; Kabir, A.; Boudjadar, S.; Aida, M.S. Review effects of the substrate temperature and solution molarity on the structural opto-electric properties of $\mathrm{ZnO}$ thin films deposited by spray pyrolysis. Mater. Sci. Semicond. Process. 2009, 12, 207-211.

19. Castañeda, L.; Garcia-Valenzuela, A.; Zironi, E.P.; Cañetas-Ortega, J.; Terrones, M.; Maldonado, A. Formation of indium-doped zinc oxide thin films using chemical spray techniques: The importance of acetic acid content in the aerosol solution and the substrate temperature for enhancing electrical transport. Thin Solid Films 2006, 503, 212-218.

20. Castañeda, L.; Morales-Saavedra, O.G.; Acosta, D.R.; Maldonado, A.; Olvera, M.L. Structural, morphological, optical, and nonlinear optical properties of fluorine-doped zinc oxide thin films deposited on glass substrates by the chemical spray technique. Phys. Status Solidi A 2006, 203, 1971-1981.

21. Castañeda, L.; Morales-Saavedra, O.G.; Cheang-Wong, J.C.; Acosta, D.R.; Bañuelos, J.G.; Maldonado, A.; Olvera, M.L. Influence of indium concentration and substrate temperature on the physical characteristics of chemically sprayed ZnO:In thin films deposited from zinc pentanedionate and indium sulfate. J. Phys.Condens. Matter. 2006, 18, 5105-5120. 
22. Castañeda, L.; Maldonado, A.; Cheang-Wong, J.C.; Rodríguez-Baez, J.; López-Fuentes, M.; Olvera, M.L. Formation of fluorine-doped zinc oxide thin films using chemical spray techniques: Effect of acetic acid content in the aerosol solution on the physical properties. Mater. Sci. Semicond. Process. 2012, in press.

23. Castañeda, L.; Maldonado, A.; Escobedo-Morales, A.; Avendaño-Alejo, M.; Gómez, H.; Vega-Pérez, J.; Olvera, M.L. Indium doped zinc oxide thin films deposited by ultrasonic spray pyrolysis technique: Effect of the substrate temperature on the physical properties. Mater. Sci. Semicond. Process. 2011, 14, 114-119.

24. Castañeda, L.; Avendaño-Alejo, M.; Márquez-Beltrán, C.; Maldonado, A. Physical properties of titanium-doped zinc oxide thin solid films grown by sol-gel method. Int. J. Mater. Eng. Technol. 2010, 4, 147-159.

25. Castañeda, L.; Silva-González, R.; Gracia-Jiménez, J.M.; Hernández-Torres, M.E.; Avendaño-Alejo, M.; Márquez-Beltrán, C.; Olvera, M.L.; Vega-Pérez, J.; Maldonado, A. Influence of aluminum concentration and substrate temperature on the physical characteristics of chemically sprayed $\mathrm{ZnO}$ :Al thin solid films deposited from zinc pentanedionate and aluminum pentanedionate. Mater. Sci. Semicond. Process. 2010, 13, 80-85.

26. Castañeda, L. Influence of colloidal silver nanoparticles on the novel flower-like titanium dioxide oxygen sensor. Sensor. Mater. 2009, 21, 25-36.

27. Castañeda, L.; Maldonado, A.; Olvera, M.L. Sensing properties of chemically sprayed $\mathrm{TiO}_{2}$ thin films using Ni, Ir, and Rh as catalysts. Senser. Actuator. B Chem. 2008, 133, 687-693.

28. Castañeda, L. Effects of palladium coatings on oxygen sensors of titanium dioxide thin films. Mater. Sci. Eng. B 2007, 139, 149-154.

29. Castañeda, L. Present status of the development and application of transparent conductors oxide thin solid films. Mater. Sci. Appl. 2011, 2, 1233-1242.

30. Smith, A.; Rodriguez-Clemente, R. Morphological differences in $\mathrm{ZnO}$ films deposited by the pyrosol technique: Effect of HCl. Thin Solid Films 1999, 345, 192-196.

31. Warren, B.E. X-ray Diffraction; Dover: New York, NY, USA, 1990; p. 253.

(C) 2012 by the authors; licensee MDPI, Basel, Switzerland. This article is an open access article distributed under the terms and conditions of the Creative Commons Attribution license (http://creativecommons.org/licenses/by/3.0/). 